Ann. Zootech., I967, 16 (I), 89-II5

\title{
CONSERVATION DES GUFS DE POULE ET ÉCLOSIVITÉ. ESSAI DE COMPARAISON AVEC LES DONNÉES OBTENUES SUR LA CONSERVATION DES CEUFS DE CONSOMMATION
}

\author{
B. SAUVEUR \\ Station de Recherches avicoles, \\ Cenire national de Recherches zootechniques, 78-Jouy-en-Josas
}

\section{SOMMIAIRE}

La conservation prolongée des œufs à couver s'accompagne à la fois d'une détérioration des constituants de l'ouf et d'une diminution du pouvoir d'éclosion. Cette observation justifie les nombreuses recherches effectuées depuis une vingtaine d'années pour essayer d'en fixer les conditions optimales.

La conservation des œufs de consommation pose également des problèmes qui peuvent différer légèrement dans la mesure où il s'agit d'œufs infertiles. Cependant il nous a semblé qu'il pourrait être intéressant de rapprocher les deux séries d'études afin de voir si la seconde ne pourrait pas éclairer quelques points encore obscurs de la première.

Disons tout d'abord quelques mots des critères habituellement utilisés dans chaque catégorie.

Les résultats d'incubation s'expriment de façon très satisfaisante par le rapport du nombre de poussins obtenus sur le nombre d'œufs fertiles placés en incubateur ; le taux de fécondité n'étant pas connu, il est essentiel de le déterminer avec le plus de précision possible. On peut pour cela pratiquer des examens micro- ou macroscopiques du disque germinatif ou des mirages; les premiers obligent à casser l'œuf et ne sont pas applicables ici. Restent les mirages dont l'intérêt dépend du stade de développement de 1'œuf. Au r 8 e jour d'incubation les embryons qui ne se sont développés que quelques heures sont totalement lysés et le mirage ne donne pas de renseignement. Le mirage précoce semble être la seule méthode précise applicable : effectué aux environs du $5^{\mathrm{e}}$ jour, il donne une précision de $90 \mathrm{p}$. Ioo environ. On améliore la précision en mirant l'œuf au bout de I $_{5}$ heures d'incubation et en utilisant des sources lumineuses colorées et plus intenses. KING (I936) obtient alors une 
précision de 95 p. 100 avec une source de 500 watts. D'après OLSEN et KNox (I938) 75 watts suffisent si la lumière traverse des filtres jaune et bleu-ve:t superposés. Ces mêmes auteurs font remarquer cependant que le stade optimum de mirage dépend de la nature de l'œuf : $\mathbf{r} 6$ heures avec les œufs blancs et $\mathrm{I} 8$ heures avec les œufs roux.

De nombreux critères peuvent être utilisés pour apprécier la qualité d'un œuf de consommation : épaisseur de la coquille, index de jaune, caractéristiques de l'albumen, test organoleptique etc. Nous retiendrons l'étude des caractères physiques de l'albumen ferme qui sont particulièrement affectés par le stockage et reflètent par conséquent l'état de fraîcheur de l'œuf.

Deux critères d'appréciation furent mis au point en r936 : l'épaisseur de l'albumen ferme (WILGus et Van WagENEN) et l'index d'albumen (HEIMAN et CARVER) obtenu en divisant l'épaisseur de l'albumen ferme par sa largeur moyenne. Les auteurs trouvent entre les caractères précédents et la qualité interne de l'œuf (estimée par une graduation subjective allant de I à 5) des coefficients de corrélation de 0,934 et 0,932 respectivement. La corrélation entre les cleux critères est elle-même très élevée 0,986 . Sans contester la valeur des chiffres précédents HaUGH apporte en I939 une modification à ces mesures. Il trouve préférable pour des études de conservation, de relier la qualité au logarithme de la hauteur d'albumen $h$. Ainsi la qualité d'un ouf exprimée en Unités Haugh est donnée par: UH $=$ Ioo $\log h$. HAUGH établit cette formule en n'utilisant que des oufs de $56,5 \mathrm{~g}(2 \mathrm{oz})$. Or la hauteur du blanc ferme est fonction du poids de l'œuf. C'est pourquoi HaUgh définit une hauteur " équivalente " $\left(\mathrm{H}_{2}\right)$, hauteur prérue pour un œuf de $56,5 \mathrm{~g}$ mais ayant le mème poids relatif d'albumen que l'œuf étudié de poids $\mathrm{W}$. Cette hauteur $\mathrm{H}_{2}$ peut être calculée par:

$$
\mathrm{H}_{2}=\mathrm{H}_{w}-\frac{\mathrm{G}\left(30 \mathrm{~W}^{1,33}-\mathrm{I} 00\right)}{\mathrm{I} 00}+\mathrm{I}, \mathrm{I} 9
$$

$\mathrm{H}_{\mathrm{w}}=$ hauteur lue (en mm),

$\mathrm{G}=$ constante gravitationnelle $=32,2$,

$\mathrm{W}=$ poids de l'œuf en coquille (en g).

Ainsi la formule de HAUGH devient :

$$
\mathrm{U} . \mathrm{H} .=\mathrm{IOO} \log . \quad \mathrm{H}-\frac{\left(\dot{r}\left(30 \mathrm{~W} \mathrm{~W}^{0,3 i}-\mathrm{IOO}\right)\right.}{\mathrm{IOO}}+\mathrm{I}, \mathrm{I} 9
$$

$o u$, en remplaçant $G$ par sa valeur :

$$
\text { U. H. }=\text { I00 } \log \cdot\left(\mathrm{H}+7,57-\mathrm{I}, 7 \mathrm{~W}^{0,37}\right)
$$

C'est sous cette forme que la méthode des Unités Haugh s'est développée; elle sera très souvent citée dans la suite de cet article comme test de qualité de l'œuf de consommation. Rappelons que 4 grancles classes d'œufs ont été établies aux U. S. A. d'après les mesures d'Unités Haugh.

$\begin{array}{ccccc}\text { Qualité AA } & \text { Unités Haugh de } 79 \text { à } & \text { I00 } \\ - & \text { A } & - & \text { de } 55 \text { à } & 78 \\ - & \text { B } & - & \text { de } 32 \text { à } & 54 \\ - & \text { C } & - & \text { moins de } & 3 \mathrm{I}\end{array}$

Les œufs de cette dernière catégorie ne devraient plus être commercialisés. 
PREMIÈRE, PARTIE

\section{CONDITIONS DE CONSERVATION DES CEUFS, ÉCLOSIVITÉ E'T CARACTÉRISTIQUES INTTERNES DE L'CEUF}

\section{I. - 'Température de STOCKAGE}

Il semble qu'une température de stockage comprise entre Io et $15,5^{\circ} \mathrm{C}(50$ à $60^{\circ} \mathrm{F}$ ) soit la plus favorable pour l'éclosivité (OLSEx et HAYNES I948; FUNK et

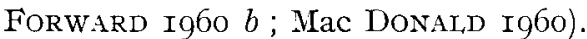

Olsen et HAynes (I948) montrent que le froid est préjudiciable à la survie de l'embryon : alors que $8 \mathrm{I}, 5$ p. Ioo des cufs fertiles éclosent après un stockage de 2 à 4 jours à $\mathrm{ro}^{\circ} \mathrm{C}, 5^{8} \mathrm{p}$. Ioo seulement arrivent à ce résultat si la température de stockage est de - ro C. Bien que Funk, Forward et Krmpster (I950) ne constatent pas de chute d'éclosivité en gardant pendant 2 jours des oufs à moins de $0^{\circ} \mathrm{C}$, il ne semble donc pas qu'une telle température soit recommandable.

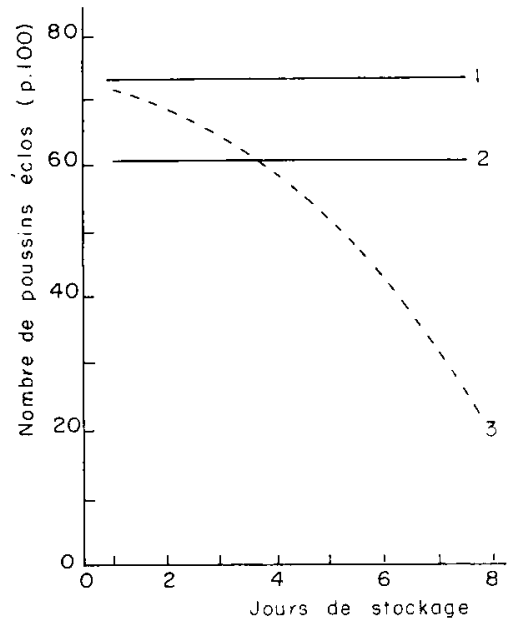

FIG. r. - Infuence de la tempéralure et de la duré de stockage sur l'éclosizisité des ants (d'apres II $\mathrm{CC}$ DOxiLD, I960)

Courbe r. - Température de stockacre de $15,5^{\circ} \mathrm{C}$

Courbe 2. - Température de stokage de $4,4^{\circ} \mathrm{C}$

Courbe 3. - l'emperature de stockagre de $26,6^{\circ} \mathrm{C}$

Des températures élevées sont également défavorables : Mac DoNaLD (I960) montre qu'après 7 jours de stockage à $27^{\circ} \mathrm{C}, 1^{\prime}$ 'éclosivité baisse de $40 \mathrm{p}$. Ioo (fig. I). Une telle chute n'a rien d'anormal si l'on se souvient que le "zéro physiologique " de l'embryon, c'est-à-dire le point oì commence son développement, est compris entre 20 et $2 I^{\circ} \mathrm{C}$ (IANDAUER, I96I). 
Pour les oufs de consommation les recommandations de température sont les mêmes et comprises entre Io et I5 ${ }^{\circ} \mathrm{C}$ (1)AWSON I956 ; FRY et NEWELL I957 ; HENDERSON et LORENZ I95I). Il semble du moins que la perte d'unités Haugh soit minimum si ces conditions thermiques sont respectées. Citons en exemple une constatation de FRY et NEWEL, (I957) : un stockage de 7 jours à $5^{\circ}{ }^{\circ} \mathrm{C}$ provoque moins de détérioration de l'albumen cqu'un stockage d'un seul jour à $32^{\circ} \mathrm{C}$. STADEI et DARRoch (I954) étudiant des températures de 35,25 , I 5 et $5^{\circ} \mathrm{C}$ trouvent un coefficient de régression linéaire de - I, I5 Unités Haugh par I $0^{\circ} \mathrm{C}$ d'accroissement de la température.

En conclusion, une température de stockage comprise entre Io et $\mathrm{I}_{5.5}{ }^{\circ} \mathrm{C}$ semble recommandable pour préserver à la fois l'éclosivité et la structure de l'albumen des œufs.

\section{II. - HUMIDITÉ REIATTIVE; DE L'ATMOSPhÈRE}

Les pores de la coquille cle l'ouf sont suffisamment larges pour permettre des échanges gazeux. Il importe donc de contrôler l'humidité de l'atmosphère cle conservation pour réduire les pertes d'eau ; celles-ci sont en effet proportionnelles à la différence entre roo (exactement 99,6) et 1'humidité relative de l'air (BRoOKs et TAYLOR, I955). Bien que toutes fondées sur ce principe, les études effectuées sur le stockage des œufs à couver fournissent des résultats assez variables. Cooney (I943) recommande une H. R. de go p. Ioo; cependant, du fait d'un développenent possible de moisissures, il est souvent préférable de se limiter à 70 ou 80 p. IOo (MERritT I964; BECKER, Ig64).

Il en est de même pour les oufs de consommation : KORSLuxd, MAariox et STADEimaN (1956) démontrent qu'une humidité relative de 90 p. Ioo est préférable à 30 p. Ioo pour préserver la qualité de l'œuf mesurée en Unités Haugh mais ils ne trouvent pas de différences économiques significatives à toutes les valeurs intermédiaires. Quelques auteurs recommandent des valeurs de 80 à 85 p. IOO (LArsox, I956; HENDERSON et LORENZ, I95I). Seuls Van Wagentex, Hai, et Ai,TManN (I939) estiment prudent de ne pas dépasser 60 p. Ioo.

Retenons que la meilleure humidité est donc celle qui, étant la plus élevée pos sible, ne permet pas le développement des moisissures; elle semble comprise entre 70 et 8 o p. Ioo.

\section{III. - INELULNCE DE IA DURIF DH CONSERVATION}

Un premier résultat est certain : 1'éclosivité des aufs diminue quand le temps de stockage augmente. Pour MERRI'T' (I964) cette diminution intervient dès le I er jour mais est surtout sensible à partir du ise jour (figure 2). Si BoHrEx, CrITTENDEN et KING (I96I) trouvent de même une baisse d'éclosivité dès le I ${ }^{\mathrm{er}}$ jour, beaucoup d'auteurs admettent qu'un stockage inférieur à 7 jours est assez peu nocif (SCOT', I933; LANDAUER, I96I).

L'effet moyen d'une augmentation d'un jour de stockage dans les conditions standard de température et d'humidité définies plus haut, et pour des conservations de 3 semaines environ, a été calculé à plusieurs reprises Les résultats sont les suivants (tab1. I).

L'augmentation de la mortalité embryonnaire est responsable de la diminution du taux d'éclosion. BrNG et NASH (Ig62) estiment qu'une augmentation d'un jour 
de stockage accroît la mortalité embryonnaire de 0,85 p. roo. D'autres auteurs aboutissent à des résultats analogues : MERRITT (I964) et ScotT (I933). BECKER (I963)

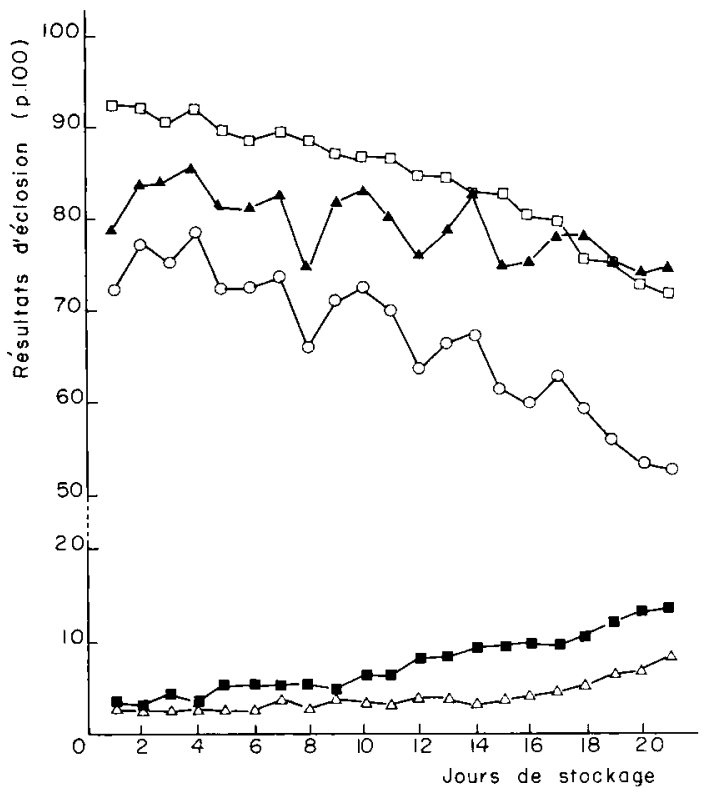

FIG. 2. -- Résultats d'incubation en fonction du slockage (d'après MERritT, I964)

-A Iiertilité

$\square-\square$ Éclosion des fertiles

O-O Eclosion du total

- - Morts à 22 jours

$\Delta \rightarrow \Delta$ Morts à is jours

\section{TABLEAU I}

Effet d'une augmentation d'un jour de stockage

\begin{tabular}{|c|c|c|}
\hline & $\begin{array}{l}\text { Sur l'éclosivité de } \\
\text { tous les œulfs }\left(\begin{array}{l}0 \\
0\end{array}\right)\end{array}$ & $\begin{array}{l}\text { Sur l'éclosivité des } \\
\text { oufs fertiles (en } \% \text { ) }\end{array}$ \\
\hline $\begin{array}{l}\text { BYNG et NASH }(1962) \ldots \\
\text { MERRITT }(1964) \ldots \ldots \ldots \\
\left.\text { IAX }{ }^{(}\right)(1964) \ldots \ldots \ldots\end{array}$ & $\begin{array}{l}-1,35 \\
-1 \\
-1,19\end{array}$ & $\begin{array}{l}-1,65 \\
-1,2 \\
-1,19\end{array}$ \\
\hline
\end{tabular}

(1) LAX n'avait pas trouvé d'œufs non fertilisés.

précise que cette mortalité survient surtout au début du développement embryonnaire. On ignore cependant par quel processus la conservation des œufs affecte ainsi la viabilité de l'embryon. 
Un autre fait mérite d'être noté : le stockage prolongé des ceufs allonge la durée d'incubation. CriT'TENDEN et BOHREN (I96r) ont calculé que chaque jour de stockage entraîne un allongement de 0,7 heure de la durée d'incubation. Des résultats du même ordre sont obtenus par KAN et al. (I962), VLAdimirova (I96I) et Funk (I934) dont les conclusions sont résumées sur la figure 3 .

BOHREN, CRITTENDEN et KING (I96I) tentent de relier la chute d'éclosivité à cet allongement de l'incubation. Ils choisissent trois durées arbitraires d'incubation de $2 \mathrm{I}, 2 \mathrm{I} \mathrm{I/2}$ et $22 \mathrm{I} / 4$ jours et étudient les pourcentages d'œufs éclos à ces dates. Leurs conclusions sont les suivantes : "à $2 \mathrm{I}$ et $2 \mathrm{I}$ I/ $2 \mathrm{j}$ d'incubation l'effet du stockage sur l'éclosivité est dû principalement à l'allongement de l'incubation... " A 22 I/4 jours cependant, l'éclosivité n'est plus liée à la seule date d'éclosion; donc "à $22 \mathrm{I} / 4 \mathrm{j}$ l'éclosivité doit être affectée par le temps de stockage d'une autre manière que par l'allongement du temps d'incubation ". L'autre facteur intervenant alors pourrait être simplement l'augmentation de mortalité embryonnaire précoce déjà signalée.

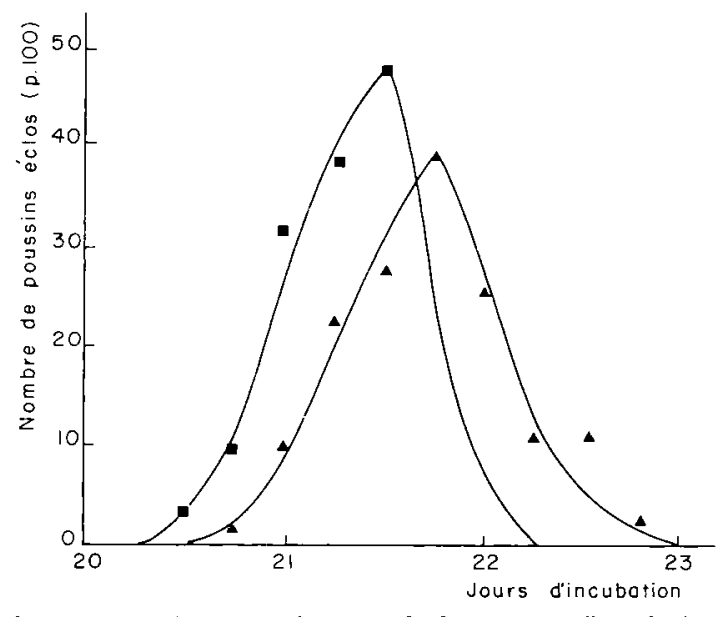

FIG. 3. - Effet du stockage sur la longueur de l'incubation (d'après Funk, 1934)

- Eufs vieux de r à 7 jours

- Eufs vieux de 8 à I 4 jours

Il y a une trentaine d'années, de nombreux auteurs avaient déjà fait le rapprochement entre l'éclosivité et la vitesse de développement de l'embryon ; Hays et Nicoraides (I934), Mac NALLy et Byerly (I936) signalent qu'un développement rapide de l'embryon est en général attaché à une éclosivité élevée. KAUFMaN (I938) pense que l'initiation du développement embryonnaire est retardée à la suite du stockage, d'où une réduction de la taille de l'embryon entre 7 et I4 jours et une augmentation de la mortalité embryonnaire. Cette hypothèse est confirmée par les travaux de NEEL (I942) qui trouve une corrélation de 0,77 entre la vitesse de développement de l'embryon et l'éclosivité.

L'âge de l'embryon au moment de la ponte de l'ceuf peut également affecter la vitesse de développement embryonnaire et, par conséquent l'éclosivité. On conçoit en effet que le temps d'incubation requis sera d'autant plus réduit que l'embryon est à un stade plus avancé au moment de la ponte. C'est ainsi que Kosin (I956 et 
I964) explique une grande part des différences de viabilité constatées entre les embryons. HAys et Nicolaides (I934) de leur côté, observent que des oufs contenant au moment de la ponte des embryons à un stade plus précoce que la gastrula donnent des résultats d'éclosion inférieurs à ceux pondus à un stade plus avancé. Le phénomène est identique à celui rapporté par STurkiE et WirLiams (I945) qui essaient d'incuber des cufs prélevés directement dans l'oviducte : dans tous les cas l'éclosivité est très faible et bien souvent il n'y a même pas développement.

Selon MAC NAILY et BYeriy (I936) le stade optimum de développement après $4^{S}$ heures d'incubation, serait de I9 à 20 somites (figure 4). De leurs études sur les œufs de dinde, OLSEN et MARSDEN (I950) déduisent également que les embryons les plus avancés après 24 heures d'incubation, donnent les meilleurs résultats d'éclosion $(87,6$ p. roo contre 28,4 p. Ioo pour les embryons jugés les plus en retard à 24 heures d'incubation).

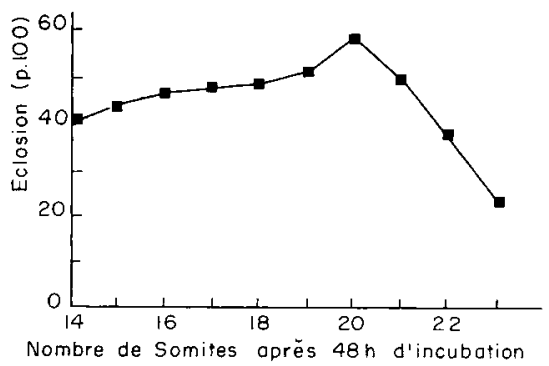

Fis. +. - In/luence du nombre de somiles de l'embryon de $48 \mathrm{~h}$. sur l'éclosivité d'après Mac Nably et Bierly (I936).

Il semble donc qu'il existe réellement un rapport entre la vitesse de développement de l'embryon et l'éclosivité ; ceci explique les succès souvent remportés par la pré-incubation. Cette technique repose sur le fait que l'exposition brève des œufs à des températures de l'ordre de $37,7^{\circ} \mathrm{C}$ favorise le développement de l'embryon en compensant le retard dû au stockage. La durée totale d'incubation est ainsi ramenée à une valeur normale. Plusieurs techniques ont été décrites donnant un résultat favorable; KAN et al. (I962), FUNK (I954), BECKER et BEARSi (I958), LAX (I964) ... chauffent les oufs 3 à 5 heures à $37,7^{\circ} \mathrm{C}$ le jour qui suit la ponte. LAX (Ig64) trouve ainsi une augmentation d'éclosivité de 3,39 p. I00 $\pm \mathrm{I}, \mathrm{I} 7 \mathrm{p}$. roo et constate en effet que la durée d'incubation des œufs les plus vieux est diminuée. Kosin (I956) fait la même remarque et note de plus une augmentation substantielle du nombre de somites en début de développement. Il fait cependant remarquer qu'un tel chauffage pourait parfois être néfaste si l'embryon était déjà à un stade optimal au moment de la ponte de l'œuf. Ceci pourrait expliquer les résultats, apparemment contradictoires, trouvés par quelques auteurs.

Selon JAcksox (I9I2), Kosin (I956) et des résultats récents obtenus à la Station expérimentale du Magneraud,' un chauffage d'une heure par jour pendant toute la durée de conservation serait préférable au chauffage continu de 5 heures décrit ci-dessus. Einfin FUNK et FORWARD ( 1960 a) recommandent un chauffage de 3 à 5 heures dans les 24 heures qui précèdent la mise en incubateur. 


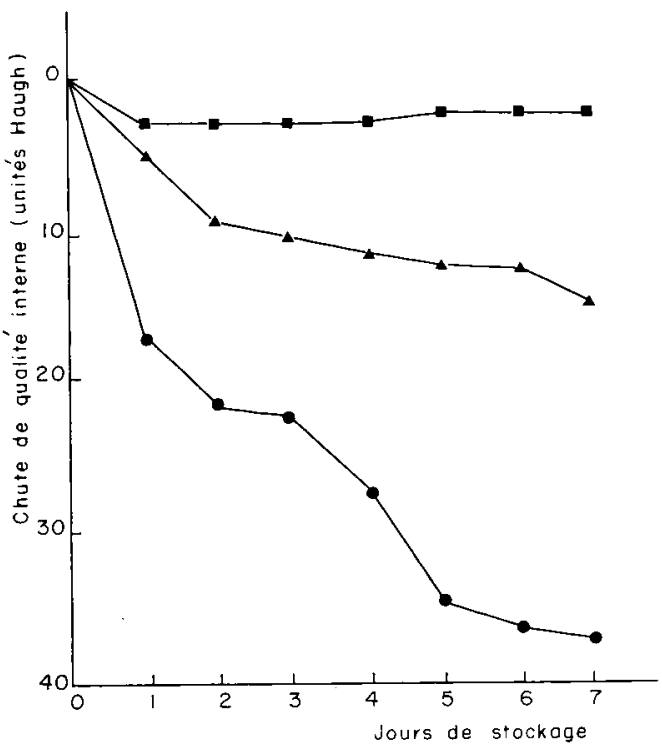

FIG. 5. - Influence de la température de stockage sur la qualité interne de l'auf (d'apres FRY et NEWELL, 1957)

-1- Température de stockage de $-\mathrm{r}, \mathrm{I}^{\circ} \mathrm{C}$.

Température de stockage de $15,5^{\circ} \mathrm{C}$

- - Température de stockage de $\quad 3^{2,2^{\circ} \mathrm{C}}$

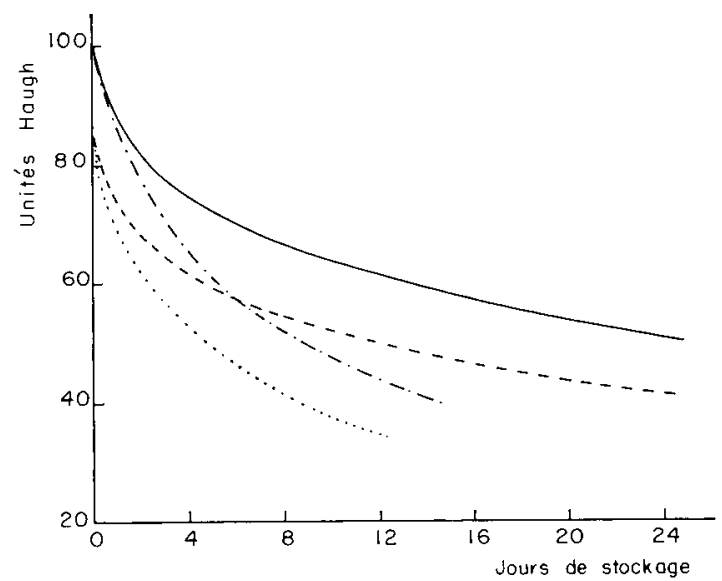

FIG. 6. - Influence de la température de stockage et de l'âge de la pouie sur la qualité interne de l'aut (d'après Borstein et Lipstein, I96a)

- Eufs de poulettes stockés à $15^{\circ} \mathrm{C}$

- - Eufs de poules stockés à ${ }^{\circ} 5^{\circ} \mathrm{C}$

-..- Eufs de poulettes stockés à $32^{\circ} \mathrm{C}$

....... Eufs de poules stockés à $32^{\circ} \mathrm{C}$ 
Les avis diffèrent également quant à l'efficacité de la pré-incubation en fonction de 1'âge de l'ouf. KAx, Mac Phersox et Gyiss (I962) et Becker et Be.arse (I958) trouvent la préincubation efficace si les œufs sont stockés de 2 à 3 semaines, ce qui s'accorde bien avec toutes les remarques antérieures. Cependant Fuxi et ForWARD (I960 a) et PRITSKER (I940) ne trouvent cette intervention intéressante que pour des ceufs de moins de 5 jours.

Signalons enfin le résultat obtenu par FUNK et ForwAR1) (I960 $a$ et $b$ ) et BECKER et BEARSE ( 1958 ) : le simple maintien cles cufs à la température de la pièce pendant les 24 heures qui précèdent la mise en incubation, entraine une augmentation d'éclosivité. Ceci se comprend aisément puisqu'un tel séjour supprime en partie la perte de temps liée au réchauffement obligatoire des œufs de $12^{\circ} \mathrm{C}$ (température de stockage) à $37,7^{\circ} \mathrm{C}$, température de $1^{\prime}$ incubateur.

On peut se demander clans quelle mesure. la chute du taux d'éclosion au cours du stockage s'explique par des modifications des caractéristiques internes de l'wuf.

Les courbes de décroissance des Unités Haugh de l'œuf en fonction du temps de conservation ne ressemblent pas à celles de baisse d'éclosivité puisque la chute des UH est surtout importante dans les premières 48 heures et que son allure générale est exponentielle: HaUgh (I939), Wilheim (I939), FRY et NEWEI I, (I957) et Borsters et LiISTEIN (I962) (fig. 5 et 6). Comme le font remarquer Borsteis et LiPSTEIN (I962) la chute de qualité ne se produit pas immédiatement mais débute après 6 heures de conservation.

\section{IV. - IMPOR'TANCE DE I'ATMOSPHìRE DE CONSERVATION}

\section{Rapport entre la structure de l'albumen et son contenu en $\mathrm{CO}_{2}$}

Au cours d'un stockage les ceufs subissent une perte importante de gaz carbonique, étudiée par de nombreux auteurs.

NEEDham et al. (I93I) étudiant des œufs infertiles ne trouvent pas de consommation d'oxygène mesurable et en déduisent que le $\mathrm{CO}_{2}$ produit n'est pas le résultat d'une respiration aérobie. Par ailleurs, Commos (I94I) ne détecte aucune activité d'anhydrase carbonique dans l'œuf en coquille. Il convient donc de rechercher ailleurs que dans les carbonates de la coquille l'origine du $\mathrm{CO}_{2}$ produit.

Schol, I. ( 893 ) décèle la présence d'ions bicarbonates dans l'albumen et pense que ce milieu ressemble au sérum sanguin. BROOKs et PACE (I93S), reprenant cette hypothèse, démontrent qu'en effet les protéines de l'albumen réagissent à line addition d'acide par une combinaison reversible avec les ions $\mathrm{H}^{+}$- si cet acide est $\mathrm{H}_{2} \mathrm{CO}_{3}$, nous avons :

$$
\mathrm{P} r^{-}+\mathrm{H}_{2} \mathrm{CO}_{3} \rightleftarrows \mathrm{HP} r+\mathrm{HCO}_{3}^{-}
$$

Le sens d'évolution de cet équilibre est essentiellement fonction de la teneur de l'atmosphère en gaz carbonique. La concentration de l'albumen en ions $\mathrm{HCO}_{3}{ }^{-}$ peut s'exprimer en fonction $\mathrm{du} \mathrm{pH}$ et de la pression partielle de $\mathrm{CO}_{\mathbf{2}}$ dans ce milieu. La relation est la suivante :

$$
\mathrm{pH}=6,37+\log \frac{\mathrm{I}, \mathrm{I} 25\left[\mathrm{HCO}_{3}^{-}\right]}{0,03} \mathrm{PCO}_{2}^{-}-0, \mathrm{I} 2
$$

Annales de Zootechnie. - i967. 
dans laquelle :

$6,37=\mathrm{pK}_{1}=\mathrm{I}^{\mathrm{re}}$ constante de dissociation de $\mathrm{H}_{2} \mathrm{CO}_{2}$.

$0,03=$ constante de la loi de Henry pour $\mathrm{CO}_{2}$ et eau pure (en mole/litre/atm.)

$\mathrm{P}_{\mathbf{c o 2}}=$ pression partielle de $\mathrm{CO}_{2}$ dans l'albumen en atm.

$-0, \mathrm{I} 2=\gamma \mathrm{HCO}_{3}{ }^{-}=$coefficient d'activité de $\mathrm{HCO}_{3}{ }^{-}$.

$\left[\mathrm{HCO}_{3}{ }^{-}\right]=$concentration de l'albumen en bicarbonates (en ion gramme/litre de blanc).

Pour HEALy et Priter (I925) le $\mathrm{CO}_{2}$ est représenté dans l'albumen par des bicarbonates mais également par une autre forme. liffectivement Brooks et PACE (I938) montrent qu'il s'y trouve à l'état dissous: en retranchant du $\mathrm{CO}_{2}$ total le $\mathrm{CO}_{2}$ combiné (essentiellement des bicarbonates), ils trouvent que le coefficient de solubilité Bunsen du $\mathrm{CO}_{2}$ dans le blanc est de $0,7 \mathrm{I}$, valeur supérieure de $8 \mathrm{p}$. Ioo au chiffre théorique calculé en tenant compte des sels minéraux présents et qui pourrait être due aux traces de lipides de l'albumen. STRAUB et JOACK (I)34) estiment à $55 \mathrm{mg}$ par cuf la quantité totale de $\mathrm{CO}_{2}$ ainsi présente.

Nous voyons done que le $\mathrm{CO}_{2}$ dégagé par les œufs au cours de leur conservation a au moins deux provenances possibles : libération du gaz dissous et décomposition des bicarbonates.

Quel est donc le rapport entre la structure de l'albumen et son contenu en $\mathrm{CO}_{2}$ ? MUEIrLR (1956 et I959) trouve, dans deux expériences différentes, des coeffcients de corrélation de - o,34I et - o,378 entre la perte de $\mathrm{CO}_{2}$ et le titre en Unités Haugh de l'wuf. Ils apparaissent clairement sur les figures 6 et 7 (MULI I ER, I958).

Il est probable que la perte de $\mathrm{CO}_{2}$ influence l'état de l'albumen en permettant une élévation du pH. MUELLER (I958) trouve en effet que le pH de l'albumen est lié à la teneur en $\mathrm{CO}_{2}$ de ce milieu par la relation :

$$
\mathrm{pH}=4,27 x+9, \mathrm{II} \quad x=\text { teneur en } \mathrm{CO}_{2} \text { en } \mathrm{mg} \cdot \mathrm{g} \text {. d'albumen. }
$$

(Voir figure 8.)

Ceci justifie la liaison trouvée entre le titre en Unités Haugh et le pH de l'albumen par IDAVis et BRECKI ER (I962) et BORSTEIN et LIPSTEIN (I962). Notons toutefois que les Unités Haugh diminuant plus lentement que n'augmente le $\mathrm{pH}$, celui-ci ne peut constituer un test valable de vieillissement.

Nous avons vu au début de cette étude quelle était l'importance globale de la température pour la conservation des oufs; voyons son action au niveau du $\mathrm{CO}_{2}$ ou du $\mathrm{pH}$ de l'albumen.

Shary (I937), SMITH (r93I) et plus tard CotTERIIL et al. (I958) constatent que la perte de $\mathrm{CO}_{2}$ est accélérée si la température de conservation s'élève et expliquent ceci par le fait que la solubilité du $\mathrm{CO}_{2}$ dans l'albumen évolue en raison inverse de la température. MUELLER (I958) aboutit aux mêmes conclusions (figure 7). Fin comparant cette figure à la figure 9 (BORSTEIN et LIPSTEIN, I962) nous voyons que l'élévation du $\mathrm{pH}$ est tout à fait parallèle au dégagement de $\mathrm{CO}_{2}$.

\section{Importance de la composition de l'atmosphère de conservation}

I a solubilité du $\mathrm{CO}_{2}$ ou sa transformation en ions bicarbonates dans l'albumen sont surtout fonctions de la pression partielle de ce gaz dans l'atmosphère. Fin contrôlant cette 


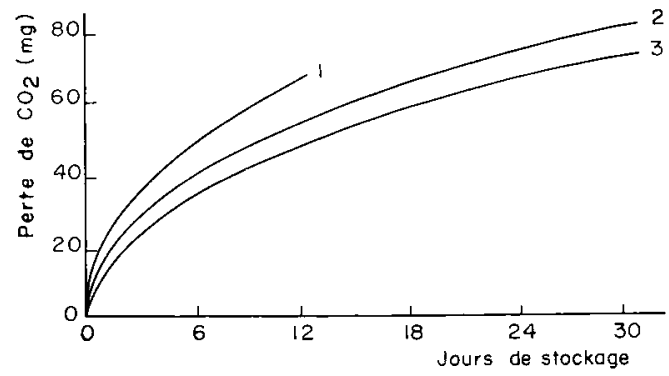

FIG. 7. - Perle de C(U) par l'wuf durant le stockage (d'aprés Muelier, I958)

Courbe I. - Température de stockage de $30^{\circ} \mathrm{C}$

Courbe 2. - Température de stockage de $24^{\circ} \mathrm{C}$

Courbe 3. - Temperature de stockage de $12^{\circ} \mathrm{C}$

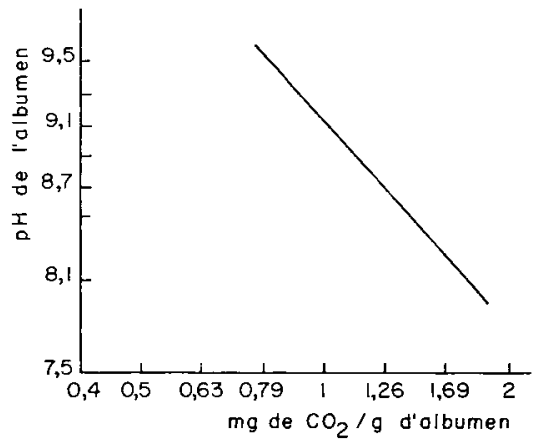

FIG. 8. - Evolution du pll de lalbunen en forudion de son contenu en $\mathrm{CO}_{3}$ (d'aprés MUELLer, i958)

Expérience effectuée sur des ceufs stockés de 3 heures is 30 jours

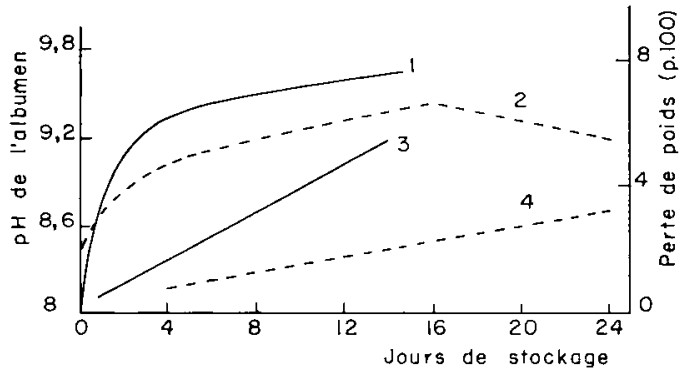

Fig. 9. - Évolution du pII de l'albumen en fonction du stockage (d'aprés BoRSTEIN et Lipstein, ig6z)

- . I $\mathrm{pH}$ ̀̀ $3^{\circ} \mathrm{C}$

$--2 \mathrm{pH}$ à ${ }_{1}^{\circ} 5^{\circ} \mathrm{C}$

-.... 3 perte de poids $\dot{a} 3^{\circ} \mathrm{C}$

-... - 4 perte de poids as $15^{\circ} \mathrm{C}$ 
dernière il doit donc être possible d'assurer à l'albumen une teneur en $\mathrm{CO}_{2}$ maximum pour une température donnée. BRooks et PACE (I938) obtiennent ainsi les résultats suivants :

TABLEAU 2

Érolution du pll du blane el de sa concentration en ions bicarbonates en fonction de la teneur en $\mathrm{CO}_{\mathbf{2}}$ de l'atmosphère

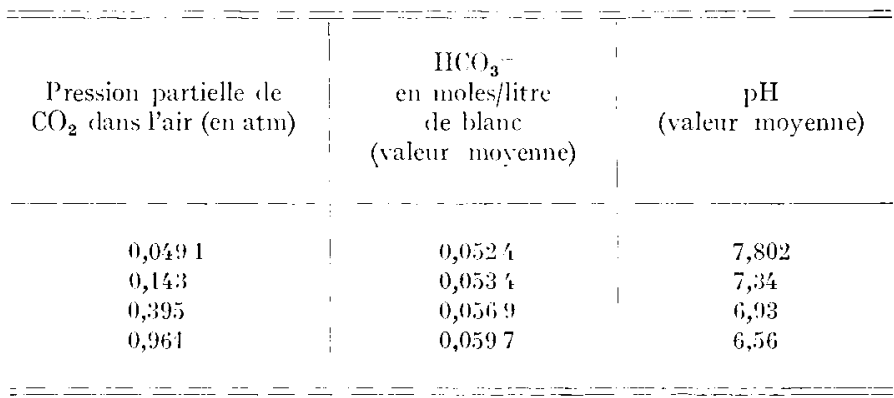

Connaissant ces valeurs, il est possible dans la relation (2) vue plus haut d'éliminer le facteur $\mathrm{HCO}_{3}$ - et d'obtenir ainsi une expression directe de la liaison entre $\mathrm{P}_{\mathrm{CO}_{2}}$ et $\mathrm{pH}$; $\left(\mathrm{P}_{\mathrm{CO}_{2}}\right.$ étant, rappelons-le, la pression partielle de $\mathrm{CO}_{2}$ dans le mélange gazeux en équilibre avec l'albumen, exprimée en atm.). BRooks et PACE (I938) trouvent alors:

$$
\mathrm{pH}=6,25+\log . \frac{0,0652-6, \mathrm{I} \times \mathrm{IO}^{-3}(\mathrm{pH}-6,55)}{0,0337 \mathrm{PCO}_{2}}
$$

à $25^{\circ} \mathrm{C}$ et dans l'intervalle $\mathrm{P}_{\mathrm{cos}_{2}}=0,05$ à $\mathrm{I}$ atm.

Pour les valeurs de $\mathrm{P}_{\mathrm{CO}_{2}}$ inférieures à $0,05 \mathrm{~atm}$. il faut tenir compte de la dissociation des $\mathrm{HCO}_{3}^{-}$en $\mathrm{CO}_{3}^{--}$qui devient importante. Mais nous voyons que ce seuil de 0,05 atm. de $\mathrm{CO}_{2}$ est suffisant pour conserver à l'œuf un $\mathrm{pH}$ très proche de celui de la ponte (alors que dans 1'air à $0,03 \mathrm{p}$. Ioo de $\mathrm{CO}_{2}$ le $\mathrm{pH}$ atteint très vite 9,5 et plus). La relation (3) permet également de savoir quel pourcentage de $\mathrm{CO}_{2}$ il faut mettre dans l'atmosphère pour obtenir un $\mathrm{pH}$ quelconque.

SMrTH (I93I) obtient des résultats concordants et parvient à éviter l'élévation de $\mathrm{pH}$ de l'albumen avec les données suivantes :

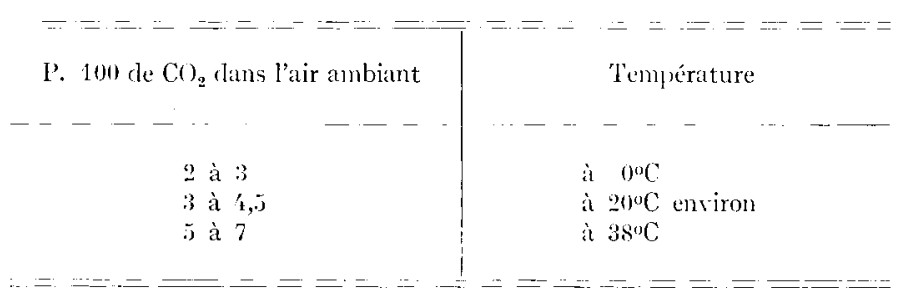

SHARP (I929) recommande une teneur en $\mathrm{CO}_{2}$ de 3 p. Ioo à $0^{\circ} \mathrm{C}$ et I2 p. Ioo à la température de la pièce. Cette valeur de I2 p. IOo, utilisée par CoTTERILI, et G.ARDNER (I957) pendant 4 jours avant une conservation en atmosphère normale, donne des résultats très encourageants.

a) Application à la conservation des oufs de consommation.

Depuis plusieurs années de nombreux essais d'emballage des ceufs ont été effectués en vue de réduire le dégagement gazeux. D'après les résultats de Davis et 
Brecklitr ( 1962 ) et de GARDNer et al. (Ig6I) il semble que le chlorure de polivinylidène (ou "Cryovac ") permette une bonne stabilisation du $\mathrm{pH}$ interne, au moins égale à celle obtenue par huilage.

Citons quelques autres chiffres illustrant l'intérêt de l'emballage des œufs pendant leur conservation :

- Selon Davis (I 959) des ceufs conservés zo jours sous polyéthylène conservent une qualité (exprimée en Unités Haugh) iclentique à celle d'œufs nus après 4 jours (toutes conditions égales par ailleurs).

- ORR et SNYDER (I959) : après 6 mois de stockage sous Cryovac la moyenne des Unités Haugh d'une série d'œufs n'a diminué que de 80 à 68 .

Il a été essayé à plusieurs reprises d'enrichir en $\mathrm{CO}_{2}$ l'atmosphère interne de ces emballages; FLETCHER et al. (I959), SWANSON et HELBACKA (I954) arrivent ainsi à conserver des œufs à peu près intacts pendant plusieurs semaines $\left(6\right.$ pour le $2^{\mathrm{e}}$ groupe d'auteurs). FLEITCHER et al. (I959) notent toutefois qu'en prenant comme référence l'odeur er le goût, la qualité des oufs ainsi conservés était inférieure à la normale. Swanson et al. (r957) ont exposé des oeufs au $\mathrm{CO}_{2}$ avant de les huiler; là encore la conservation est meilleure qu'après huilage seul.

L'effet bénéfique des divers emballages n'est peut-être pas dû uniquement à la réduction de perte de $\mathrm{CO}_{2}$ et il est possible que la diminution de perte d'eau intervienne également. Selon GARdxER et al. (I96I) et MUEI.I.ER (I936 et I959) la réduction de la perte d'eau jouerait cependant un rôle beaucoup moins important.

MUELI,LR démontre en effet que la corrélation entre 1'amincissement de 1'albumen et la perte d'eau n'est pas significative alors que celle se rapportant à la perte de $\mathrm{CO}_{2}$ l'est au niveau I p. Ioo.

Dans une autre expérience il trouve bien une corrélation de - o,55 entre le nombre d'Unités Haugh et la perte d'eau mais attribue simplement cela à la corrélation existante entre perte d'eau et perte de $\mathrm{CO}_{2}(+0,53)$.

Au cours du stockage des cufs il se produit un passage d'eau lent de l'albumen vers le jaune; ce transfert hydrique est dî̀, d'une part aux variations de pression osmotique entre ces deux zones, et d'autre part, à des modifications d'épaisseur et de rigidité de la membrane vitelline.

BRoOks et TAYIOR (I955) rapportent qu'un jaune contenant en moyenne $8,5 \mathrm{~g}$ d'eau, en absorbe $0,005 \mathrm{~g} / \mathrm{jour}$ de conservation à $\mathrm{o}^{\circ} \mathrm{C}$ et 2 fois plus à ro $0^{\circ} \mathrm{C}$. Cette légère hydratation a un très gros effet sur la viscosité du jaune comme l'indiquent les chiffres suivants:

TABI.EAU 3

Viscosité relative du jaune en fonction de sa teneur en eau

\begin{tabular}{|c|c|}
\hline $\begin{array}{l}\text { Eau du jaune } \\
\text { en p. } 100\end{array}$ & $\begin{array}{l}\text { Viscosité relative du } \\
\text { jaune }(\text { eau }=1)\end{array}$ \\
\hline 47,2 & 100 \\
\hline 50,0 & 32,7 \\
\hline $5^{\prime}, 0$ & 10,5 \\
\hline 57,6 & 3,5 \\
\hline
\end{tabular}


MORAN (I937) montre que ce phénomène peut être combattu par l'emploi d'atmosphères faiblement enrichies en $\mathrm{CO}_{2}$ (2 à Io p. IOO) :

TABLEAU 4

$V$ ariation de l'index de jaune en fonction de la teneur en $\mathrm{CO}_{2}$ de l'atmosphere de conservation.

\begin{tabular}{|c|c|}
\hline & $\begin{array}{l}\text { Index de jaute } \\
\text { (hauteur/largeur) }\end{array}$ \\
\hline Valeur initiale. & 0,45 \\
\hline $\mathrm{A}_{1}$ rès $25 \mathrm{j}$. de conservation dans l'air à $25^{\circ} \mathrm{C}$ & 0,30 \\
\hline$A_{\text {près }} 5 \mathrm{1} / 2$ mois dans l'air à $0^{\circ} \mathrm{C} \ldots \ldots$ & 0,40 \\
\hline$\Lambda$ prés $\Rightarrow 1 / 2$ mois dans $2,5 \% \mathrm{CO}_{2}$ ì $0^{\circ} \mathrm{C}$. & 0,15 \\
\hline$A_{\text {P rès }} 51 / 2$ mois dans $10 \% \mathrm{CO}_{2}^{\circ}$ à $0^{\circ} \mathrm{C}$. & 0,45 \\
\hline Après 5 1/2 mois dans $60 \% \quad C_{2}^{\circ}$ à $0^{\circ} \mathrm{C}$. & 0,43 \\
\hline
\end{tabular}

Citons enfin les résultats de MUEL, ER (I959) qui démontrent que tous ces phénomènes de détérioration sont liés : il trouve une corrélation hautement significative (égale à 0,59 ) entre la perte d'Unités Haugh du blanc et le mouvement de l'eau à l'intérieur de l'œuf.

b) Application à la conservation des xufs à cowver.

S'inspirant de très nombreuses études précédentes effectuées sur les wufs de consommation, BECKER (Ig64) et BECKER, SPEACER et SWARTWOOD (I964) essaient de conserver sous emballage des ceufs fertiles de White Leghorn avant leur incubation. Après un stockage de 2 semaines les éclosivités sont les suivantes :

\begin{tabular}{|c|c|c|}
\hline tockage & sous Cryovac. & 80,6 p. Ioo (des cufs fertiles) \\
\hline & sous polyéthylène. & 75,9 p. IOO \\
\hline - & à nu. & 0,3 p. 100 \\
\hline
\end{tabular}

WARREN, RoFF et LoNg (I965) retrouvent cet effet bénéfique de l'emballage pour des conservations de plus de I3 jours mais font remarquer que dans les conditions usuelles de stockage ( $\mathrm{r}$ semaine environ) la rentabilité de cette technique est très discutable. BECKER et al. (I964) expliquent les améliorations obtenues par la réduction de perte de $\mathrm{CO}_{2}$ sans préciser quel mécanisme interne intervient. Peut-être est-ce par le biais des transferts d'eau du blanc au jaune cités plus haut?

Ce rôle possible du gaz carbonique de l'albumen sur l'éclosivité a incité plusieurs auteurs à essayer des atmosphères de stockage enrichies en $\mathrm{CO}_{2}$. Proudfoot ( $964 a$ et $b$ ) utilise des « emballages de Cryovac gonflés au $\mathrm{CO}_{2}$ sous pression 》 et trouve alors des résultats d'éclosivité catastrophiques de l'ordre de Io p. Ioo. VLadimirova (I 962) employant des atmosphères à 50 p. Ioo de $\mathrm{CO}_{2}$ constate un effet favorable sur l'éclosivité d'œufs d'oies; malheureusement ses résultats sont fondés sur un très petit nombre d'œufs. Nous avons vu précédemment que de faibles pressions partielles de $\mathrm{CO}_{2}$ dans l'atmosphère $(2$ à $5 \mathrm{p}$. Ioo) étaient suffisantes pour maintenir certaines caractéristiques de l'œuf telles que le $\mathrm{pH}$ de l'albumen ou la viscosité du jaune. Peut-être en est-il de même pour l'éclosivité? 
Notons pout terminer que des essais d'emballage contenant une atmosphère enrichie en azote ont été effectués par Gowe (I965) et Proudfoot (I964 $b$ ) pour des conservations de 3 semaines environ. I)ans tous les cas l'éclosivité se trouve améliorée d'environ Io p. Ioo par rapport à une conservation sous Cryovac rempli d'air. Ce phénomène n'est pas encore clairement expliqué ; Arora (Ig63) constate un développement blastodermal plus rapide après un tel stockage mais n'explique pas comment cette atmosphère azotée aurait pu le provoquer.

Nous arrêterons ici cette étude comparative des conditions de conservation des oufs fertiles et infertiles. Nous espérons avoir fait entrevoir quelques relations possibles entre éclosivité et structure de l'albumen. Afin d'augmenter le nombre des points de comparaison nous allons maintenant étudier les variations de l'éclosivité et cles caractéristiques de l'albumen en fonction de facteurs autres que la conservation en signalant toutefois l'effet de leur interaction avec celle-ci. 

DEUXIÈME PAR'TIE

\section{QUELQUES FACTEURS D'ÉCLOSIVITÉ ET DE QUALITÉ DU BLANC DE L'CEUF LIÉS A L'ANIMAL}

Nous nous limiterons à quelques remarques sur l'effet de facteurs " morphologiques et physiologiques " tels que le poids de l'œuf, l'âge de la poule ou l'intensité de sa production. Ein terminant il sera dit quelques mots de variations d'origine génétique.

\section{I - Intervention du poids de l'reuf}

A durée d'incubation égale, de nombreux travaux ont démontré l'existence d'une liaison inverse entre le poids de l'œuf et l'éclosivité. Citons notamment ceux de Coles (I956), Bohren, CritTenden et King (I96I) ; L)UnN (I922), trouve déjà les chiffres suivants:

TABLEAU 5

Taux d'élosizité en fonction du poids de l'auf

\begin{tabular}{|c|c|}
\hline l'oids de l'uruf $(g)$ & P. 100 d’éclosivité des oeufs fertiles \\
\hline $52-59,9,9$ & $62,06 \pm 2,53$ \\
\hline $60 \cdots 73,4$ & ${ }^{4} t^{\prime}, 09 \pm 5,1^{\prime}$ \\
\hline
\end{tabular}

Il existe entre les 2 groupes une différence d'éclosivité de I7,97 $\pm 5,88$ (3 fois l'écart-type) qui est significative.

I) Uxy (I922) précise (comme le font également BoHREN et al., I96r) que cette propriété est surtout valable à l'échelle individuelle mais CoLEs (I956) l'a retrouvée inter et intra-poules. Si les gros oufs sont défavorisés, les plus petits le sont également comme l'ont montré HALBERSEBEN et Mussehl (I92I) et Axeisox (I932) dont les résultats sont reportés sur la figure ro.

Il est d'autre part connu que les gros œufs réclament un temps d'incubation supérieur. Nous pouvons donc admettre, à la suite de BoHrex et al. (Ig6r) et CriT'TENDEN et BOHREN (I96r) que le poids de l'œuf affecte l'éclosivité comme le fait la conservation. Ceci est confirmé par les résultats de GARTLEY et al. (I95I) : ils démontrent que les effets nocifs de l'âge ou du poids d'un œuf sont détruits de la même façon en incubant ces œufs 6 à I 8 heures de plus que les témoins. LAx (Ig64) obtient un effet compensateur semblable en pré-incubant les cufs les plus gros.

Annales de Zootechnie $-19^{6} 7$. 
Notons cependant que le poids de l'œuf agit peut-être également en modifiant le rapport : volume de 1'œuf/surface de la coquille qui joue un rôle important dans les phénomènes d'évaporation.

Signalons enfin que Arbolede, RaNit et YNiguez (Ig60) et Tindell et Morris (I964) ne trouvent pas d'influence significative du poids de l'œuf sur l'éclosivité.

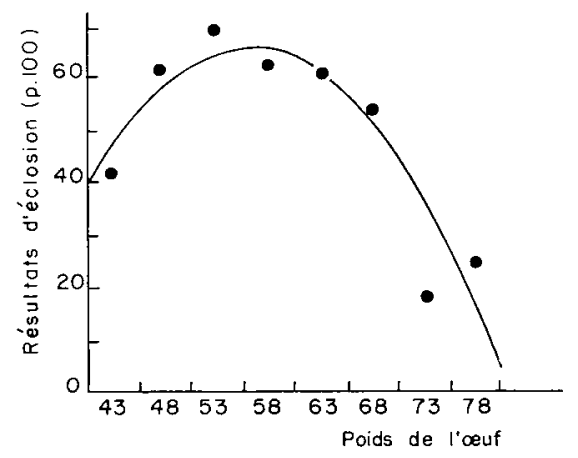

Fic. то. -- Régression du pourcentage d'éclosion sur le poids de l'euf (en g.) (l'après AxELson, 1932)

Le poids d'un ouf et sa qualité interne exprimée en Unités Haugh sont liés de façon formelle puisque le poids intervient dans le calcul de ces unités ; (revoir au début de cet article).

La relation de cause à effet entre ces deux caractères semble cependant être assez faible. Tel est du moins l'avis de YaO (I958) et de Borstein et IIISTEIn (I962), dont les consclusions sont résumées dans le tableau 6 :

\section{TABIEAU 6}

Facteurs ayant une action sur les Unités Haugh

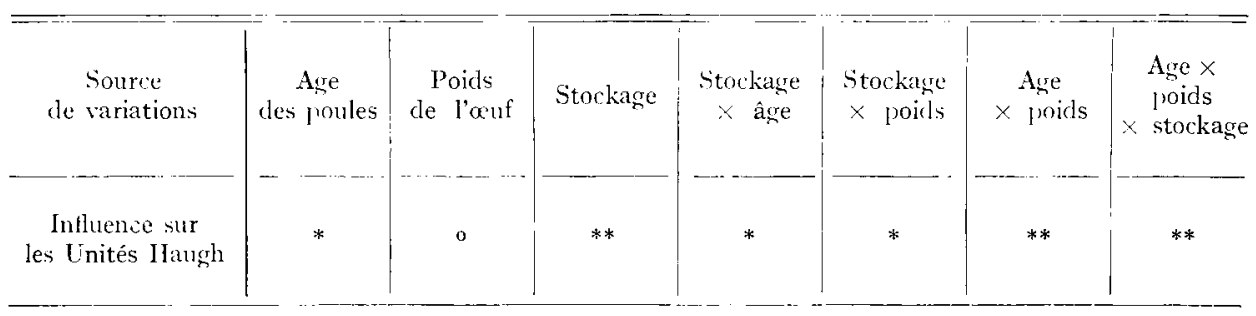

$0=$ le facteur consideré n'a pas d'infuence significative sur les U.II.

* = influence simuificative au niveau $5 \mathrm{p}$. 100

** = influence significative au nivea 1 p. 1011

Notons enfin que la diminution des Unités Haugh au cours du stockage ne dépend pas non plus du poids initial de l'ouf (MUELLER I959).

Retenons donc que si l'éclosivité d'un ceuf dépend de son poids, ce doit être par une voie différente de la qualité interne. 


\section{II - Intervention de l'âge de la pondeuse}

Nous pouvons constater sur le tableau 6 que l'âge des poules exerce un effet significatif sur la qualité initiale des œufs mesurée en Unités Haugh.

L'analyse statistique révèle également le rôle de l'interaction Age de la poule $\times$ Poids de l'œuf explicable par la liaison existant entre ces deux facteurs. Ceci confirme les résultats de nombreux auteurs qui constatent une baisse très nette de qualité

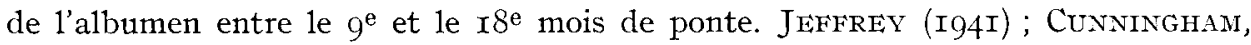
COTTERIL, et FUNK (I960) (figure II) ; YAO (I958) ; etc.

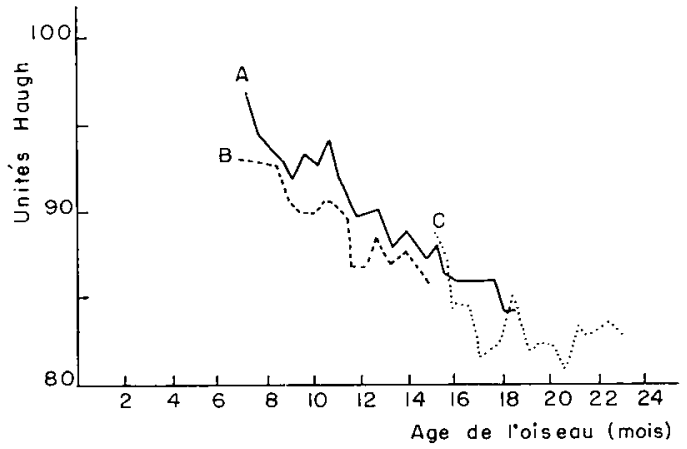

FIG. II. - In/luence de l'âge de la poule sur la qualité inteme de l'wuf (l'après Cunxiscilan et al., 1960)

A. - Animaux âgés de 7 mois en début d'expérience

B3. - Animaux âgés de 4 mois

C. - Animaux âgés de i 5 mois

Cependant Fronisg et Funk (I958) et MARCh et BIELY (I96I) pensent que la chute de qualité de l'albumen a surtout lieu dans les premiers mois de ponte. Ie même LAHELIEC (I965) enregistre une diminution des Unités Haugh durant les 5 premiers mois de ponte, suivie d'une stabilisation.

Selon Sryder (I957) et la courbe 6 de BorStFin et Lipstein (I962), le taux de décroissance des Unités Haugh pendant le stockage ne serait pas lié à l'âge de la poule. Ceci est cependant en contradiction avec les résultats de MAY et al. (I957) et de MUELLER (I959) qui trouvent une corrélation de o,8 I5 entre la diminution des Unités Haugh lors du stockage et la valeur initiale de l'albumen. Nous avons vu en effet que celle-ci dépend étroitement de l'âge de l'animal.

Des travaux de NEEI. (I942) et LANDAUER (I96I) nous pouvons déduire que l'éclosivité des oufs et la vitesse de développement de l'embryon sont liés significativement à l'âge de la poule. 'l'omhave (1956, I958) précise que la chute d'éclosivité intervient après 225 à 250 jours de ponte, soit environ 8 mois. L'âge critique est donc le même que dans le cas des pondeuses productrices d'œufs de consommation. LAA (1964) approfondit la comparaison et déclare à propos des travaux de Tommave: " La baisse d'éclosivité des œufs en fonction de l'âge de la poule est probablement due à de nombreux facteurs parmi lesquels les plus importants pourraient être la diminution de qualité interne de l'œuf et l'augmentation de sa taille. " LAX, démontrant de plus que l'effet défavorable de 1'âge de la pondeuse sur l'éclosivité est annulé si on allonge l'incubation ou si l'on fait un préchauffage, réalise donc un début de synthèse des idlées exposées jusqu'ici. 


\section{III - Influence du niveau de production de la pondeuse}

Il semble exister une liaison inverse entre le niveau de production de la pondeuse et la qualité de l'albumen des œufs : JeFfrey (I94I), Johnsox et MerritT (I955). Ces derniers auteurs, étudiant des poulettes White Leghorn et Barred Rocks trouvent dans les deux cas une corrélation phénotypique négative entre la hauteur d'albumen et la production d'oufs. Une telle liaison n'est cependant pas unanimement reconnue : King et Hair. (I955), Sxyder (I957) et Pope et al. (I960) ne constatent pas d'influence de l'intensité de ponte sur la qualité des oufs.

Les résultats (peu nombreux) obtenus sur les cufs à couver sont totalement opposés! Byeriy, 'Titus et ELIIS (I933) et FUNK (I934) constatent une liaison positive faible mais significative entre le niveau de production et l'éclosivité. A propos de ces études IANDAUER (I96I) fait cependant remarquer : " I)e telles corrélations, si elles existent, peuvent refléter l'action de facteurs qui agissent à la fois sur la production et l'éclosivité " (sans que la première soit donc responsable de la seconde). "Elles peuvent aussi résulter d'autres facteurs tels que par exemple, la tendance des coqs à féconder plus souvent les poules fortes productrices que celles qui pondent peu. Il existe alors entre les deux groupes une différence dans l'âge du sperme qui pourrait être responsable de beaucoup de variations. "

NALBANDov et CARD (I943) et Kosin (I947) démontrent en effet que des spermatozoïdes vieux de plus de I j jours, s'ils conservent encore leur pouvoir de féconder les œufs, donnent des résultats d'éclosion plus faibles que des spermatozoïdes moins âgés.

S'il ne semble pas possible de conclure quant à l'influence du niveau de production de la pondeuse nous pouvons en revanche rapprocher deux autres séries de travatux. WARREN (I934) constate une différence significative d'éclosivité entre des œufs provenant de poules auxquelles on a imposé un arrêt de ponte et d'autres pondus par des animaux en production continue, l'avantage revenant aux premières. MARBLE (I963) étudiant les classements U.S. D). A. des cufs (la méthode U. S. D. A. définit 4 qualités d'œuf (AA, A, B et C) en fonction de l'aspect du blanc et du jaune comparé à des photographies de référence) obtient les chiffres rapportés au tableau 7 :

TABIEAU 7

Évolution de la qualité interne de l'œuf en fonction de l'âge de la poule

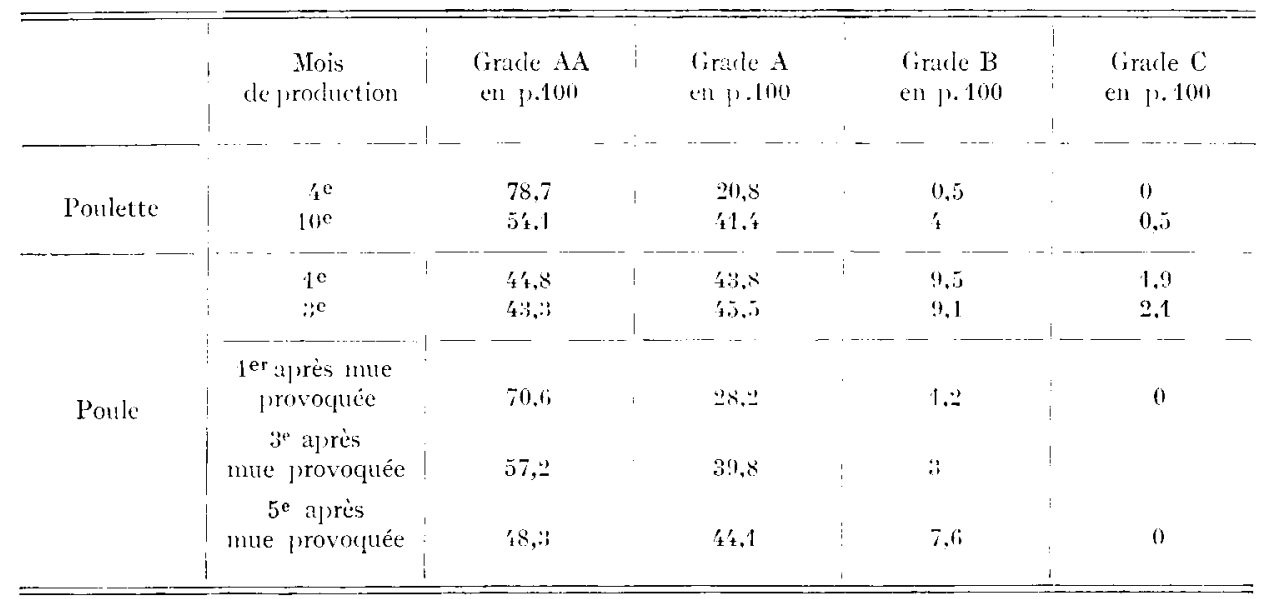


La mue provoquée ou arrêt de ponte provoqué a donc un effet très net sur la structure de l'albumen. Nous constatons en effet que pendant les deux mois qui la suivent les œufs sont à peu près de même qualité que ceux d'une poulette d'un an. Mais la deuxième année le déclin des Unités Haugh est plus rapide.

Retenons donc qu'un arrêt de ponte provoqué semble être bénéfique du double point de vue de la qualité interne et de l'éclosivité des oufs.

\section{IV - Interaction de quelques facteurs d'origine génétique}

Il existe des variations considérables tant à l'échelle de l'individu, qu'à celle de la souche et peut-être même de la race. Commençons par citer un exemple relatif à ce dernier facteur. KING et HALL, (I955) font remarquer que les New Hampshire semblent donner des œufs ayant une qualité d'albumen très supérieure à la moyenne ; SAUTER et al. (I954) constatent d'autre part que cette qualité se conserve beaucoup mieux après un stockage de 5 semaines à $72^{\circ} \mathrm{F}\left(22,2^{\circ} \mathrm{C}\right)$ si les cufs proviennent de poules Ner Hampshire plutôt que de White Leghorn. Or selon PHILIIPS (I945) ces mêmes New Hampshire ont en général de très bons résultats d'éclosion et OL,SEN (I95I) affirme que l'éclosivité cle leurs œufs est celle qui est la moins affectée par un stockage à $\mathrm{o}^{\circ} \mathrm{C}$. (condition de température aussi peu favorable que l'étaient les $22^{\circ} \mathrm{C}$ utilisés par SAUTER et al.).

L'interprétation de tels résultats est délicate car à l'intérieur de chaque race les souches sont des sources de variation fort importantes. May, SchmidT et STADELMAN (I957) et COTTERIII, et WINTER (I934) entre autres auteurs trouvent des différences significatives entre souches en ce qui concerne aussi bien la qualité initiale du blanc que son aptitude à la conservation.

BoHREN et CRITTENDEN (I96I) d'autre part déduisent de leur travaux que les souches (ou les individus) pondant des oufs à incubation "courte " auront des résultats d'éclosion supérieurs aux autres après stockage, puisque celui-ci agit partiellement en allongeant 1'incubation. Mriby (1960) précise de même que certains œufs "génétiquement supérieurs" n'ont pas besoin de pré-incubation pour compenser l'action néfaste de la conservation.

Il existe enfin de nombreuses variations individuelles qu'il serait trop long d'exposer ici et qui obligent souvent à ne donner que des résultats " intra-poules ". 

TROISIÈME PARTIE,

\section{ANALOGIES EXISTANT ENTRE GEUS DE CONSOMMATION ET GEUFS A COUVER. CONCLUSIONS}

Au cours des deux parties précédentes nous avons pu noter que les qualités physiques des œufs de consommation et l'éclosivité des œufs à couver évoluaient souvent de façon parallèle. Nous avons vu par exemple que la température et 1'humidité de conservation devaient être comprises dans les mêmes marges pour les deux catégories; nous avons spécialement insisté sur l'importance du gaz carbonique dans l'atmosphère de stockage et là encore il semble que les réactions globales soient les mêmes. Il resterait maintenant à voir s'il existe une liaison de cause à effet entre la qualité dı blanc (exprimée par exemple en Unités Haugh) et l'éclosivité ; malheureusement aucune étude approfondie de ce genre n'a été faite à ce jour à notre connaissance. La seule approche est celle effectuée par HAI, et Van WAGENEN en I936 : attribuant des valeurs arbitraires allant de I à 5 pour des albumens de qualité décroissante ils établissent les 2 corrélations significatives suivantes entre l'éclosivité et la valeur de l'albumen :

- 0,342 chez des oiseaux sélectionnés pour la qualité de l'albumen;

- 0,297 chez des oiseaux non sélectionnés.

Une bonne éclosivité semble donc être liée à une haute qualité d'albumen. Ces auteurs montrent également que la mortalité embryonnaire précoce serait beaucoup plus élevée chez les oiseaux sélectionnés pour une faible qualité d'albumen. A la suite de leur expérience HALL et Van WAGExEx suggèrent que tout facteur responsable de variations de qualité d'albumen pourrait également être étroitement lié avec les causes de mortalité embryonnaire précoce. Malheureusement ces résultats ont été aussitôt démentis. Selon WILHEI,M (I930) il existe bien une corrélation très élevée $(0,74)$ entre la hauteur et l'index d'albumen mais il ne trouve aucune liaison significative entre ces deux caractères et l'éclosivité.

De même Rudy et MARBLE (I939) estiment que la hauteur et la cohésion de l'albumen ne semblent pas liés à l'éclosivité. GoDHREY (I936) trouve bien une relation inverse entre le poids d'albumen et l'éclosivité mais estime avec raison que c'est en fait le poids total de l'cuf qui intervient alors.

I1 n'est donc pas possible présentement de tirer des conclusions de ces études. Retenons simplement que la qualité de l'albumen et 1'éclosivité sont modifiées simultanément par de nombreux facteurs. Bien que ce résultat ne démontre que l'exis- 
tence d'une relation indirecte entre ces deux caractéristiques de l'œuf, il permet de définir quelques orientations pour la conservation des cufs à couver : en particulier il serait logique d'essayer de stocker des cufs fertiles sous 3 à 4 p. Ioo de $\mathrm{CO}_{2}$.

Ultérieurement il restera à découvrir si la structure de l'albumen peut influencer directement l'éclosivité, ce qui conduira probablement à des études plus fondamentales sur les protéines du blanc, l'équilibre osmotique au niveau du disque germinatif, ou d'autres phénomènes non encore reliés à ce problème.

Reçu pour publication en janvier 1967.

\title{
SUMMARY
}

\author{
PRESERVATION OF HEN'S EGGS AND IIATCHABILITY. \\ COMPARISON WITI RESULTS OBTAINED IN PRESERVATION OF EGGS FOR CONSUMPTIOA
}

We have attempted to collect the references relating to preservation of eggs for incubation and of those for consumption and to show a similarity between the two techniques. The main criteria found for efficiency are the number of chicks hatched in relation to the number of fertile eggs, and HAUGi units, a method of assessing internal quality.

It seems that temperature and degree of humidity of the atmosphere in which the eggs are preserved nust be the same for all eggs. It seems also that control of the gaseous mixture for preservation, particularly the $\mathrm{CO}_{2}$ content, can ensure simultaneous maintenance of internal quality of the egg and its hatchability. Some experimental possibilities are suggested on this subject.

However, it remains clear that hatchability is not related only to the quality of the egg white as shown by measurement of HAIGH units. This is made clear by comparison of the curves showing the falls in hatchability and in internal cuality of the egg as a function of duration of storage, which show different features.

We have also collected some references concerning factors related to the hen which affect hatchability or the quality of egg white. IIere too results are variable. Thus, age of the or induced cessation of laying can affect both criteria studied in the same way. On the other hand, a high rate of production reduces internal quality of the egg but seems to have a favourable effect on hatchability.

Such findings are discussed. T'hey show the need for better knowledge of the role played by the overall structure and the different constituents of egg white in the development of the embryo.

\section{RÉFÉRENCES BIBLIOGRAPHIQUES}

Arboleda C. R., Ranit G. O., Vxiguez A. D., igoo. A correlation study of ligg size to fertility, hatchability, and Chick size, etc. Philippine Agric., 44, 247 -260.

Arora K. I.., Kosin I. I.., I 963 . The effect of different gaseous enviromments on the blastoderm in Chicken eggs stored at $25 \pm \mathrm{I}$ (C. Progr. Rep., Poultry Council, Washington State Univ., IJ 4-I I9.

AxELson J., 1932. Variation and heredity of some characters in White Leghorn, Rhode-1sland Reds Barnevelders. Part. I. Lunds Universitäts Arsskrift X. F., Avd 2, 28. n० 4, 1-196.

BECKER W. A. 1963, Length of pre-incubation storage of Turkey eggs and its effects on body weight Poultry Sci., 42, I $35^{6-\mathrm{I}} 359$.

Becker W. A., I 964 . The storage of While Leghmm hatching eggs in plastic bags. Poultry Sci., 43, i Io9III 2 .

Becker W. A., Gordon li, BeAkse, r95\%. Pre-incubation waming and hatchability of chicken eggs. Poultry Sci., 37, 944-948.

Becker W. A., Spencer J. V., SWARTwood J. L., 1964. The pre-incubation storage of Turkey eggs in closed environment. Poultry Sci., 43, $15^{26-1} 533$.

Bohren B. B., Crittenden L. B., KIng R. T., 196r. Hatching time and hatchability in the fowl. Ponltry $S c i ., 40,620-633$. 
Bornstein s., lipsters b., igo2. Some characteristics of measures employed for detemining the interior quality of Chicken egess. Brit. Poullry Sci., 3, 127-1 39 .

Brooks J., Pace J., 1938. The distribution of carbon dioxide in the Hen's egrg. Proc. r. Soc. (London), Sér. $\mathrm{B}, 126$, $196-209$.

Brooks J., TAYLoR D. J., 1955. Eggs and ligg l'roducts. Fid Invest. Sjecial Report no 60.

Byerly 'T. C., Tites H. W., lists N. R., 1933. l'roduction and hatchability of eggs as affected by different kinds and quantities of proteins in the diet of laying hens. J. agric. Res., 46, I-22.

Byng A. J., NasiI, ig62. The effects of egre storage on hatchability. Brit. Ponlliry Sci., 3. 8I-87.

Coles R., 1956 . The influence of the Hen's liggr Weight on hatching. Poully' Sci., 35, 817-822.

Commox R. II., ig4I. Carbonic anhydrase activity of the Hen's oviduct. J. agric. Sci., 31, 41 2-414.

COONEY, 1943. P're-incubation humidity variation effects on Chicken egg hatchability. Oregon Exper. Sin Tech. Bull., 2.

Cotterill O.J., Garuner 19., 1957. Retarding thick white deterioration by holding shell eggs in saled containers. Ponltry Sci., 36, ig6-206.

Cotterill O. J., Gardner F.A., Funk E. M., Cunninghan I. Ii., i958. Relationship between lemperature and carbon dioxide loss from shell egess. Poultry Sci., 37, 479-483.

Cotterili, O. J., Wister A. R., I954. Egg white lysosyme. I . Relative lysosyme activity in fresh egres having low and high interior quality. Poully Sci., 33. 607-611.

CRITTENDEN 1. 13., BOHREN 13. 33., r961. The senetic and envirommental eflects of hatching time, Egg weight and holding time on hatchability. Poully Sci., 40, I 736-1 $75^{\circ}$.

Cunningham F. li., Cotterill O. J., Funk Ji. M., 1960. The effect of season and age of bird. I. On egg size, quality and yield. Poullyy Sci., 39, $28, y-299$.

Dafis G. I., i 959 . Plastic overwraps for maintenance of egg quality. Ponlly Sci., 38, i 97 (Abstr.).

Davis G. I., Breckler A. F.: 1962. Plastic packaging of eggs. I. Hethods of packaging. Poullry Sei., 41, 391-397.

Dawson 1. K., 1956. The effects of farm refrigeration on marketable quality of eggs. Poullry Sci., 35, 586-592.

Duns L. C.., r922. The relationship between the weight and the hatching quality of eggs. Storrs Agric. Exper. Sin. Bull., 109.

Fletcher D. A., ORR I. L. et al, 1959. Effect of oiling, packaging material and condition of $\mathrm{CO}_{2}$ in quality of shell eggs in storage. Poultry Sci., 38. I06-I I I.

FroNing G. W., FUNK E. M., 1958. Seasonal variation in quality of eggs laid by cages layers and their sisters on the floor. Ponltry Sci., 37, 2 15-22.3.

FRY J. L., Newell G. W., 1957. Management and holding conditions as they affect the interior quality of eggs. Poultry Sci., 36, 2+0-246.

Fuxk L. M., I934. Factors influencing hatchability in the donestic fowl. Missouri Agric. Exper. Sin Res. Bull., 341.

Funk E. M., Forward J. li., r960 a. Effect of pre-incubation on the hatchability of Chicken eggs. Missouri Agric. Exper. Sin. Res. Bull., 695.

FUnk E. M., Forwari) J. li., 1960 b. Effect of holding temperatures on hatchability of Chicken eggs. Missouri Agric. Exper. Stn. Res. Bull., 732.

Fivk E. M., Forward J. E., KE.MPSTER H. I.,, 1950. Effect of holding temperatures on hatchability of Eggs. Missouri Agric. Exper. Sin. Res. Bull. $\mathbf{5 3 9}$.

Gardner F. A., Mlleer II. M., Courteney II. V., ig6r. The effect of overwrapping on interior egg quality. Poullery Sci., 40, I 406 (Abstr.).

Gartiey K. M., HcConacint: J. D., Cavers J. R., I95i. Relation entre l'aspect des oufs de Dinde au moment du mirage et leur éclosion. Proc. 9th World's Poult. Congr., 1, 88-93.

GODFREY A. B., I 936. The effect of egg white, quantity of total albumen per egg, and quantity of thick albumen per egg on hatchability. Poultry Sci., 15, 294-297.

Gowe R. S., 1965. On the hatchability of Chicken eggs stored in plastic bags flushed with nitrogen bags. Poullyy Sci., 44, 492-495.

Halbersleben D. L.,Musseili, F. K., I $921-1922$. Relation of eggr weight to Chick weight at hatching. Poully Sci., 1, 143-I 44.

HALL G. O., Van WaGenen A., I936. The association of certain measures of interior egg quality with hatchability. Poultry Sei., 15, 501-506.

IIAUgh R. E., 1939. Unit for measuring egg storage conditions. Proc. fth World's Poult. Congr., 525-528.

Hays F. A., Nicolaides C., 1934. Variability in development of freh-laid Hen eggrs. Poultry' Sci., 13, 74-90.

Healy D. J., P'eter A. II., i 925. Amer. J. Physiol., 74, 363. Cité par Brooks et Pace (1938).

Heimai V., Carver J. S., 1936. The albumen index as a physical measurement of observed Eggr quality. Poultry Sci., 15, I4I-I 48 .

Henderson S. M., Lorenz F. IV., i951. Cooling and holding Eggs on the ranch. Calif. Agric. Exper. Sin. Circular., 405. 
Jackson H. W., Ig12. Poultry experiments. lixperinents in incubation. Pennsylania Stale College Agric. Exper. Sin. Bull., 120, $3^{-15}$.

Jefrem F. P., I94I. Changes in pullet year albunen index as affected by age of bird. Poullry Sci., 20, 20s-3० I.

Johrsox A. S., MERrit E. S., 1955. Heritability of albumen height and s]ecific gravity of eggs from White Leghorn and Barred Rocks and the correlations of these traits with egre production. Poultry Sci., 34, $578-587$.

Kax BJ., McPnerson B. N., (jyles N. R., Ig62. P're-incubation warning on Chicken eggs. Ponllon' Sci, $41,1+78-1480$.

Kaufaax L., 1938. Jntwichlung und Wachstum von llühnerembryonen in frishen und in gelargeten Eitem. Arch. Ceflïgelkde, 12, 65-77.

KIvG D. F., 1938. Selectingr infertile eggs previous to incubation. tith Annual Report Alabana Exper. Sin.

KING s. C., HaLI (s. O., 195.5. Egg quality studies at the New York random sample test. Poultry Sci., 34, 799-809.

Korslund H. J., Marion W. W., Stadeicanan W. J., i 956. Some factors affecting the short term storage of eggrs. Poullyy Sci., 35, I 152 (Abstr.).

KosIx I. L., I 947. Preliminary results of a study on the effect of in zivo atring of spermatozoa on the viability of Chicken eggs. Poultry Sci., 26, $5+8$ (Abstr.).

Kosrs I. L., 1956. Studies on pre-incubation waming of Chicken and Turkey eggs, Poullry Sci., 35, $1384-1392$.

Kosix 1. L., Ig64. Recent research in hatchability. Related problens of the clomestic fowls. World's Poull. Sci., 20, $254-268$.

LaHELlec Cécile, s965. Contribution à l'étude des variations qualitatives de l'ueuf de poule au cours d'une saison rle ponte. Bull. Inform. Sin. exper. Avicult. Plou/ragan., 5 (30).

LANDACER W., I961. The hatchability of Chicken egress influencerl by enviromment and hereclity. Connecticul Iuric. Exp., Sin., Monograph. I.

LAx I., 1964. The effect of niating type, age of Ifen, pre-ineubation warming of eggs and age of egg on hat hability. Proc. 196t. Australasian P'oulty Sci. Convention, 91-94.

Mac Donatd M. W., ig6o. Fiffect of temperature of storage and agre of fowl egros on hatchability and sex ratio, Crowth and viability of the Chickens. Austral. J. Agric. Res., 11, $064-672$.

MaC Valey E. II., BYerey T. (`., 1936. Variation in the development of embryos of Iten's eger. I'mully' Sici, 15, $280-283$.

Magnerladu (Station lixpérimentale (li ...), 1965. Résultats non publiés.

Marber D. R., r963. Comparison of pullet and hen flocks at the New York ramblom sample test. Comell. Unia. Agric. Exper. Sha., 33.

Marcir B., Brem J., 1061. A survey of : the quality of newly laid egres on farm in British Columbia. lieedslaffs, 33-34, 3.

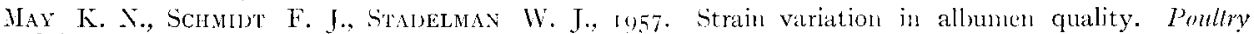
Sci., 36, г 376-1 $37 \%$.

Merri'T Ji. S., 1964. I're-incubation storage effects on subsequent performances of Chickens. Brit. P'ouliry Soi., 5. $67-73$.

Milby 'T. T., Sinerwoos, J). H., rgoo. The influence of pre-incubation tratment on hatchability of Chicken and 'Turkey eguss. I'onllyy Sci, 39, I1 Isi-1 121 .

Morax T., 1937. J. Soc. chem. Ind., Loncl., 56, 96-101.

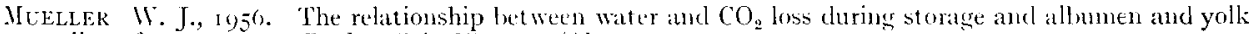
quality after storaire. Poulloy Sci., 35, 1161 (Abstr.).

Mueller W. J., I 958. Shell porosity of chicken egges. 1. $\mathrm{CO}_{2}$ loss and $\mathrm{CO}_{2}$ content of infertile eggs churing storage. Poultry ici., 37, 437-444.

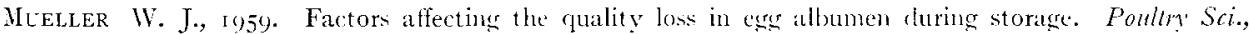
$38,+3+3+5$

Natbandov A., Carb L. li., 1943. Elfect of stale sperme on fertility and hatchability of chickene curess. Pouliry Sci, 22, 21 ì-226.

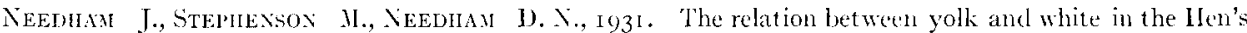
egar. IV. The formation of lactic acid and alcohol by the yolk. J.exper. Biol., 8, 3ig-320.

NEEE J. K., 1942. A calibration of the revelopment of the chick under insproved conditions of incubation... Polliny Sici, 21, 2(1)-300.

Otsen II. W., I95I. Effect of low temperatures on the hatchability of ligres from various Standard bred and crossbred Chickens. Poultry' Sci, 30, 180-183.

OLSEx M. W., IIAves S. K., igt8. The effect of different holding temperatures on the hatchability of Hen's exg. Poulliry Sci, 27, +20-126.

OLsen II. W., Kvox C. W., 1938. Farly identification of fertility in IIen's egcr. Poullry Sci., 17, $472-47 \%$

OLsex Ii. W. MARSnex $\&$. J., 1952. Variability among Turkey embryos at twenty-four hours of incubation with respect to hatchability. Ponltry sci., 29, $414-419$. 
ORR II. L., STYJer E. I., I959. A further study on the use of plastic film bags for eger storage. Poullry Sci., 38, $73^{6-737}$.

Phimses R. E., I945. Hatchability as influenced by environmental and different storage temperatures. Poultry Sci., 24, $25^{-28}$.

I'OPE C.W., Watts A. B., Williams E., Beunson C. C., ig6o. The effect of the length of time in production and storage of egs fomation on certain egg quality measurements... Poullry Sci., 39, I427-I 431.

Pritsker I. IA., I94o. The influence of high temperatures cluring the first hours of incubation. Dokly Vsesoius Akal. seslk. Vauk im. V. L. Lenina, Zootechk, $\mathrm{n}^{\circ} \mathrm{8}, 24-28$.

Protinfoot F. G., Ig64 a. The effects of plastic packitring and other treatments on hatching cygrs. Canad. J. Anim. Sci., 44, $87-95$.

Proujfoot F. G., $196+b$. The effect of nitrogren and other gazes on the hatchability of egg stored in plastic bags. Canad. J. anim. Sci., 44, 120-121.

Ronivof A. L., Romaxof A., I949. The anian egg. Wiley, Chapman et Iall.

RudY W. J., MARBLE D. R., I939. The interrclationship of physical measurements of exgrs and their effect upon hatchability. Poultry Sci., 18, 354-358.

Salter E. A., Harse J. V., Stadelmax W. J., MaC LAREx B. A., I954. Scasonal variations in quality of exus as measured by physical and functionnal properties. Poullry Sci., 33, 519-524.

Scirol. II., Isis3. Arch. Hyg., 17, 535. Cité jar Brooks et P'ACE (I938).

ScotT II. M., 1933. The effect of axe and holding temperatures on hatchability of Turkey and (hicken egress. Poultry Sci., 12, 49-5+.

SHARl' P. F., I929. 'The pII white as an important factor influencing the keeping quality of Hen's eggs. Science, 69, 278-280.

SHARP P. F., 1937. l'reservation and storage of Hem's egres. Food kes., 2, 477-498.

Surti M., 19.3I. The relations between yollli and white in the Ilen's egrg. III. Cras exchange in infertile egess. J. exper. Biol., 8, 31 2-318.

Sixytuer, 1957. Facteurs actuellement comms pour influencer la qualité de l'uuf. Onlario Canada, $29-34$.

STAIELMan W. J., Zeibler li, 'larkoch J. G., Iy5t. The effect of eger temperature on its broken out albumen quality evaluation. Poullory Sci, 33, 1082 (Alsstr.).

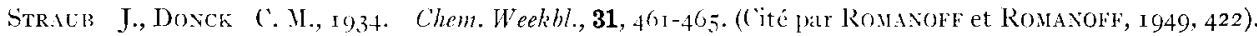

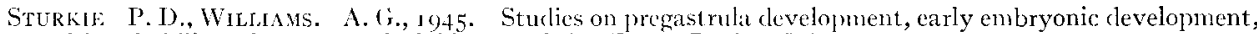
and hatchability of prematurely laid eggs of the Ilen. Poullory Sci., 24, 545-554.

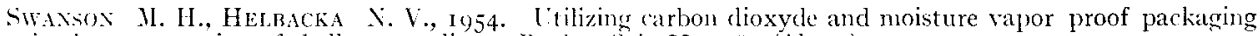
in the preservation of shell exs quality. Powlly Sci, 33. $108_{4}$ (Abstr.).

Swaviox H. H., Skila J. H., Bexsox II. X., 1957. Effect of oiling and carbon dioxide treatment at point of production on quality loss in shell egess. Poully' Sci, 36, 1 I 62 (Alstr.).

TINIELL D., MorRIs D. R., 1964. 'The effects of eggr weight on subsequent troiler performance. I'onlly' Sci., 43, $5.3 t^{-} 539$.

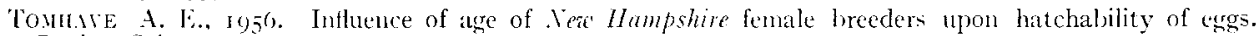
Poully Sci., 35, $23^{6-2}-238$.

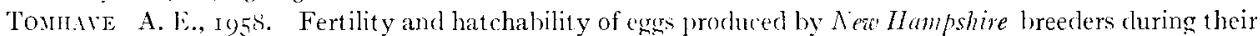
first $3^{6} 5$ days of prosluction. Poulley Sci., 37, $27^{-20}$.

Veadminova In. N.. io62. Liffect of low temperatures and of increased cartom dioxyde content in the air duriner storatre, on the hatchability of (joose and Chiclien ecress. Repraty Rabol Vsesorus. N. I. in-ta I'litsecolstita. 94-06.

Van Whienex A., IIAL (3. O., ALtuAN M., 1939. 'Temperature and humidity in the short time holding of eirss. Proc. 7th World's Poultry Congr., 516-520.

WARRFe D. C 1934 . The influence of some factors on the hatchability of the Hen's eger. Kansas Agric. Exher. Stn. Techn. Bull., 3r.

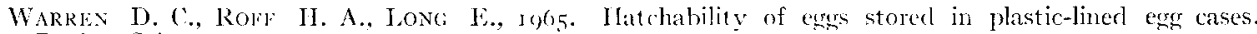
Poully Sci, 44, 1278-12So.

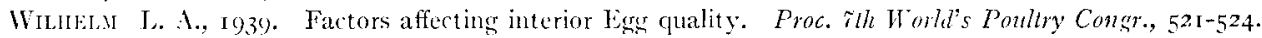

Witilitu I. A., 19.39. Effect of interior quality of exrs on their hatchability. Proc. rth World's Poultry Consr. 191-104.

Wibcis: H. S., Van Wacesex A., 10,36. The height of the firm albumen as a measure of its condition. Polltry $S a i, \mathbf{1 5}, 3$ I $9-32 \mathrm{I}$.

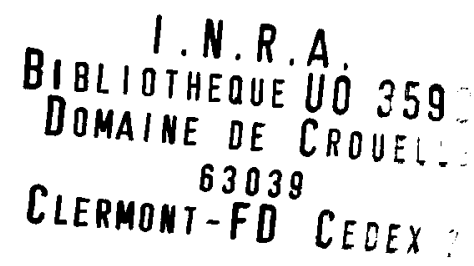

